\title{
A ficção de Milton Hatoum: recepção crítica ${ }^{1}$
}

\author{
Milton Hatoum's fiction: critical reception \\ Francisca Andréa Ribeiro da SILVA* \\ Universidade Federal do Pará (UFPA) \\ Sylvia Maria TRUSEN** \\ Universidade Federal do Pará (UFPA)
}

\begin{abstract}
RESUMO: A obra do escritor Milton Hatoum tem conquistado um número considerável de leitores nacionais e internacionais e suscitado muitas pesquisas. Diante disso, este estudo vem propor um levantamento do que críticos jornalísticos e literários vêm concebendo sobre o conjunto da ficção de Hatoum. Assim, pode-se notar uma receptividade positiva, pois tal autor tem sido visto, na maioria das perspectivas, como não regionalista, capaz de por intermédio de elementos regionais abordar em suas narrativas assuntos de caráter universal, como os conflitos familiares, a miscigenação de etnias, os conflitos gerados pelo contato entre povos nativos e migrantes, culturas negociadas, a abordagem das relações entre as alteridades étnicas e de gênero, dentre outros aspectos. Logo, este trabalho traz as diversas visões sobre a obra hatouniana.
\end{abstract}

PALAVRAS-CHAVE: Ficção de Milton Hatoum. Recepção das obras. Reconhecimento. Regionalismo/não regionalismo.

ABSTRACT: The writer Milton Hatoum's work has conquering a considerable number of national and international readers and it has stimulated many research. Therefore, this study proposes a survey of what journalistic and literary critics have been conceiving about the set of Hatoum's fiction. Thus, one can notice a positive receptivity, since such author has been seen,

\footnotetext{
${ }^{1}$ Este estudo foi realizado no intuito de colaborar na produção da dissertação Cinzas do Norte e Órfãos do Eldorado, de Milton Hatoum: vozes narrativas e alteridade na construção das personagens femininas, de autoria de Francisca Andréa Ribeiro da Silva, sob orientação da Profa. Dra. Sylvia Trusen, e defendida no mês de junho de 2017. Assim, vale ressaltar que algumas considerações desta pesquisa se fazem presentes na introdução dessa dissertação.

* Mestre em Linguagens e Saberes na Amazônia - Universidade Federal do Pará. Endereço eletrônico: andrearibsilva@ hotmail.com

** Doutora em Letras e Profa. da Universidade Federal do Pará, vinculada aos programas de pósgraduação, Linguagens e Saberes na Amazônia e Estudos Antrópicos da Amazônia. Pesquisadora do iiLER - Instituto Interdisciplinar de Leitura - Cátedra Unesco de Leitura PUC/Rio. Pós-doutoramento pela Universidade Federal do Rio de Janeiro, no Programa de Pós-Graduação Ciência da Literatura. Orientadora. Endereço eletrônico: sylviatrusen@me.com
}

Enviado em 20/07/2018 e aprovado em 25/07/2018 
in the majority of the perspectives, as non-regionalist and able, through regional elements, to approach in his narratives subjects of universal character, such as family conflicts, miscegenation of ethnic groups, the conflicts generated by the contact between native and migrant peoples, negotiated cultures, the approach of the relations between ethnic and gender alterities, among other aspects. Therefore, this work brings the different visions about the Hatounian work.

KEYWORDS: Milton Hatoum's fiction. Reception of works. Recognition. Regionalism/nonregionalism.

\section{Introdução}

Milton Hatoum, escritor que compõe a literatura brasileira contemporânea, nasceu em 1952, na cidade de Manaus, onde viveu até o ano de 1967. A partir daí, morou em outras cidades, como Brasília, São Paulo, Madri, Barcelona e Paris. Hoje, reside novamente em São Paulo ${ }^{2}$. Até o presente momento, sua obra é constituída por quatro romances (o último deles, publicado em 2017, é o primeiro de uma série, A noite da espera, que pretende abranger o período militar), uma novela, um livro de contos, um de crônica, além de várias traduções realizadas. Essas obras já foram analisadas por um número considerável de estudiosos e é disso que trataremos neste artigo, isto é, da forma como foi concebida a recepção das obras desse autor.

Segundo informações contidas no site $^{3}$ do escritor Milton Hatoum, seu primeiro livro Relato de um certo Oriente foi publicado, pela primeira vez, em 1989 e ganhou, posteriormente, o prêmio Jabuti de melhor romance. Onze anos depois, o autor trouxe aos leitores seu segundo romance: Dois irmãos, premiado em terceiro lugar, também com o prêmio Jabuti, e que já foi traduzido em idiomas variados. Em 2005, publicou seu terceiro romance Cinzas do Norte, obtendo com ele cinco prêmios ${ }^{4}$. Seu quarto livro de ficção, Órfãos do Eldorado, foi publicado em 2008, angariando o segundo lugar no Prêmio Jabuti. Em 2009, publicou A cidade ilhada - um livro de contos e, quatro anos depois, em 2013, suas crônicas foram reunidas no livro Um solitário à

\footnotetext{
${ }^{2}$ Informações biográficas conseguidas no site do autor Milton Hatoum: www.miltonhatoum.com.br ${ }^{3}$ www.miltonhatoum.com.br

${ }^{4}$ Prêmio Portugal Telecom, Grande Prêmio da Crítica/APCA-2005, Prêmio Jabuti/2006 de Melhor romance, Prêmio Livro do Ano da CBL, Prêmio BRAVO! de literatura.
} 
espreita $^{5}$. Mais recentemente, em 2017, Hatoum publicou o primeiro volume da série, $O$ lugar mais sombrio, intitulado A noite da espera, primeira parte da trilogia que entretece a história de uma família e a formação de seu protagonista ao período da ditadura militar no país. Seus livros, que possuem um número elevado de publicações, já foram traduzidos em doze línguas e publicados em catorze países, além de adaptações para o cinema e televisão. Além disso, Hatoum possui ensaios e artigos, publicados tanto em revistas e jornais brasileiros quanto em outros países.

Como se pode perceber, pelos prêmios conquistados, as obras de Milton Hatoum foram bem acolhidas pela crítica. E, também, pelo número de edições das obras e pelas diversas traduções ${ }^{6}$, notamos que houve uma boa receptividade por parte dos leitores. A venda foi acentuada, de certa forma, pelo fato de muitas universidades terem tornado a ficção de Hatoum em leitura obrigatória nos processos seletivos. Não só universidades da região norte, mas instituições de outras regiões do Brasil mostraram interesse em abraçar as produções de Hatoum, na indicação de leitura, como objeto de pesquisa, tanto em graduações quanto em pós-graduações. No exterior, também houve uma receptividade positiva. Na França, o romance Dois Irmãos foi adotado nas universidades como leitura obrigatória para os exames dos franceses para a matéria ensino de português, segundo informou Hatoum (2005) a uma entrevista dada ao Correio Braziliense. A novela Órfãos do Eldorado compõem a edição Mitos, da editora escocesa Canongate e, por isso tiveram direitos de publicação vendidos para outros

\footnotetext{
${ }^{5}$ A informação sobre o livro de crônicas foi conseguida no site da editora Companhia das Letras: www.companhiadasletras.com.br

${ }^{6}$ A obra Relato de um certo Oriente possui duas traduções em alemão: Emilie oder Tod in Manaus: Roman. Tradução: Karin von Schweder-Schreiner. Muncher/Zurich: Piper, 1992; Brief aus Manaus: Roman. Tradução: Karin von Schweder-Schreiner. Frankfurt: Suhrkamp, 2002. Em espanhol: Relato de un Cierto Oriente. Tradução: Juana María Inarejos Ortiz. Madrid: Akal, 2001. Em francês: Récit d'un Certain Oriente. Tradução: Claude Fages. Paris: Seuil, 1993. Em inglês: The tree of the Seventh Heave. Trad. Ellen Watson. New York: Atheneum; Toronto: Maxwell Macmillan, 1994; Tale of a Certain Oriente. London: Bloomsbury, 2007. Em italiano: Ricordi di un Certo Oriente. Trad. Amina di Munno. Milano: Garzanti, 1992. A obra Dois Irmãos também foi traduzida em outras línguas: Em alemão: Zwei Brüder: roman. Trad. Karin von Schweder-Schreiner. Frankfurt: Suhrkamp, 2002. Em árabe: Chaqiqan. Trad. Safa Abouchahl Jubran. Beirut: Alfarabi, 2003. Em espanhol: Dos Hermanos. Trad. Juana María Inarejos Ortiz. Madrid: Akal, 2003. Em francês: Deux fréres. Trad. Claude Fages. Paris: Seuil, 2003. Em holandês: Twee Broers. Trad. Jelle Noorman. Amsterdam: Atlas, 2004. Em inglês: The Brothers. Trad. John Gledson. London: Bloomsbury, 2002. Em italiano: Due Fratelli. Trad. Amina di Munno. Milano: Net, 2007. Em grego: Ta Adéphia. Trad. E. Uanteakhe. Atenas: Alexandria, 2005. Já Cinzas do Norte foi traduzida em italiano: Ceneri del Nord. Trad. Amina di Munno. Milano: Il Saggiatore, 2007. Tais informações foram conseguidas no seguinte link: www.elfikurten.com.br/2013/05/milton-hatoum-oarquiteto-da-memoria.html Acesso: 20 de jan de 2016.
} 
países. Essas informações demonstram, portanto, a receptividade internacional de suas obras.

\title{
1 -A crítica jornalística, literária e acadêmica
}

A partir de pesquisas realizadas em reportagens e entrevistas ${ }^{7}$ com Milton Hatoum, desde 1989 aos nossos dias, tem-se verificado diversos posicionamentos, dentre os quais, referimos alguns nas linhas que se seguem.

A reportagem Recordação da casa dos mortos (REVISTA VISÃO, 1989) revela Hatoum como um autor recém-lançado que impressionou o editor da Companhia das Letras, Luís Schwartz, por sua força e originalidade. Salienta, ainda, certo aspecto literariamente atávico em sua obra, que diz respeito ao legado das leituras do autor de As mil e uma noites, bem como dos procedimentos narrativos Faulkner, características essas reconhecidas por Davi Arrigucci Jr., crítico literário e professor de Literatura na Universidade de São Paulo (USP). Abaixo, lê-se um trecho da opinião do professor, transcrita na reportagem:

\begin{abstract}
A narração remonta ao passado por lances retrospectivos, pela voz da narradora, em que se encaixam outras vozes em coral coeso, lembrando a tradição oral dos narradores orientais: caixa de surpresas, de que saltam as múltiplas faces das personagens, em jogo de sombra e silêncio, sob a luz ardente do Amazonas. (ARRIGUCCI, 1989 apud REVISTA VISÃO, 1989)
\end{abstract}

Segundo Arrigucci Jr, a obra é tecida por uma arquitetura imaginária, em que se revela um mundo único, exótico e enigmático, envolto a estranha poesia, que possui, ademais, alto poder de convicção. Em outros termos, sustenta o crítico, embora a obra esteja envolta por certa áurea enigmática, ela mantém seu caráter verossímil.

Em outra reportagem intitulada Quando o mito vira história e a história vira mito (BRASIL DE FATO, 2010), a literatura de Milton Hatoum é destacada como arte que invoca o leitor a prestar atenção a uma Amazônia ainda desconhecida, desconstruindo os discursos cristalizados sobre a região. Nesse sentido, a opinião que se tem é que a literatura de Hatoum traça uma ruptura com os estereótipos formados sobre a região amazônica. Tal visão já se distingue do conteúdo exposto na matéria citada anteriormente, já que a mesma demonstra que a obra de Hatoum revela um mundo exótico.

\footnotetext{
${ }^{7}$ Tais reportagens e entrevistas são as que Hatoum disponibiliza em seu site.
} 
Já Carlos Graieb (1995), ao compor a reportagem Milton Hatoum cria pátria entre dois mundos, destaca que o autor, em Relatos de um certo Oriente, tem a Amazônia mais como um lugar de desejo do que um lugar geográfico:

[...] Embora para escrever esse livro o autor tenha permanecido em casa, por assim dizer, atracado ao "Manaus Harbour", a Amazônia onde se passa a história é menos um lugar geográfico que um lugar do desejo. Um lugar ficcional para o qual convergem memórias de infância, narrativas feitas por vários personagens e elementos de diferentes culturas - brasileira e libanesa às quais o autor está ligado [...]

Carlos Graieb (1995) acrescenta ainda o fato de Milton ter estudado literaturas hispano-americana e francesa, o que tem contribuído para trajetória literária do autor, imprimindo ao texto uma verticalidade e uma delicadeza na composição do enredo e das personagens. Assim, percebe-se um olhar que associa as vivências literárias do autor à construção de sua obra ficcional. Já Sereza (2000) afirma ser Hatoum um representante regional que evita o regionalismo. Em relação ao livro de contos, Aíla Sampaio (2009) afirma ter a obra a mesma qualidade dos livros anteriores e que os contos possuem uma linguagem que não foge da técnica do gênero, considerando-o hábil na produção de contos.

Luciano Trigo (2001), na entrevista intitulada Manaus, a personagem de $O$ Globo, confirma com o autor, que Manaus é retratada não apenas como matéria-prima, mas também como personagem principal - sobretudo no romance $O s$ Dois irmãos, como revela Hatoum. Além disso, anota que suas obras se elaboram a partir dos desvãos do eu, malgrado o que designa como "despistamento do eu", isto é, apesar das artimanhas e recursos da ficção narrativa que tentam apagar as marcas da história pessoal.

Nesse sentido, tais reportagens, como a de Graieb (1995) e a de Luciano Trigo (2001), atribuem características à obra de Hatoum, que destacam o teor intimista de seus textos, associando-o também, (1995), à vida do escritor.

Assim, nota-se que, no que concerne ao que foi publicado por jornalistas, a obra de Hatoum é vista de forma positiva e, na maioria das vezes, sua a ficção é entrelaçada às experiências pessoais do autor. Diante do exposto, vale indagar qual é a posição da crítica literária diante da ficção de Hatoum.

Diferentemente da maneira como a maioria das matérias jornalísticas expõem as obras de Hatoum, o crítico literário Alfredo Bosi (2013) não considera tal escritor como intimista e, também, não o inclui entre os regionalistas, como Abguar Bastos e Dalcídio 
Jurandir. O crítico e historiador comenta, em poucas linhas, a obra de Milton, ao tratar da ficção situada entre os anos 70 e 90, mostrando que a literatura desse período é marcada pela abertura às diferenças do Brasil, encenando tanto a literatura do eixo RioSão Paulo como também as do Norte e Nordeste:

\begin{abstract}
Quem supunha, por exemplo, que da Amazônia só nos viessem episódios de seringueiros ou de índios massacrados, por certo recebeu com surpresa o texto em surdina de Milton Hatoum, Relato de Um Certo Oriente (89), em que a vida de uma família burguesa de origem árabe, enraizada em Manaus, se dá ao leitor como um tecido de memórias, uma sequência às vezes fantasmagórica de estados de alma, que lembra a tradição de nosso melhor romance introspectivo.

A escrita apurada de um estreante como Milton Hatoum parece indicar (como o fizeram, nos anos 70, Raduan Nassar com Lavoura Arcaica e Carlos \& Carlos Süssekind com Armadilha para Lamartine) em que um certo ideal de prosa narrativa, refletida e compassada, que vem de Graciliano e chegou a Osman Lins, não é forçosamente fruto de um passado estético irreversível. Esse padrão resiste em meio aos cacos do mosaico pós-moderno e significa a vitalidade de um gosto literário sóbrio que não renuncia a mediação de uma sintaxe bem comportada e do léxico preciso [...] (BOSI, 2013, p. 466-467, grifos do autor)
\end{abstract}

Bosi critica positivamente a obra de Hatoum, comparando-a aos melhores romances introspectivos, pela representação da sondagem psicológica dos personagens, em busca de suas memórias. Destaca, ainda, o estilo de escrita do escritor, sem exuberâncias sintáticas e lexicais.

Outro crítico literário que discorre sobre a obra de Milton Hatoum é Benedito Nunes (2012). Durante uma entrevista dada ao jornalista Lúcio Flávio Pinto (apud NUNES, 2012), intitulada Um roteiro dos livros de um sábio paraense ${ }^{8}$, o crítico e pensador paraense foi questionado sobre quais livros a respeito da Amazônia devem constar em uma boa biblioteca, e o mesmo citou, dentre outros, a primeira obra de Hatoum. Em outra entrevista, de título Benedito Nunes ensina o caminho de volta: crítico paraense defende a radicalidade dos escritores para afirmar grandeza da Amazônia ${ }^{9}$, Nunes (2012) revela ser admirador incondicional de Hatoum, por considerálo ficcionista que se utiliza da distância como maneira eficaz de proximidade à Amazônia que é cenário de suas obras. Na pergunta feita pelo jornalista: "Qual a real

\footnotetext{
${ }^{8}$ Entrevista publicada no jornal A Província do Pará e compilada no livro Do Marajó ao arquivo: breve panorama da cultura no Pará (2012), o qual reúne entrevistas, discursos, crônicas, estudos culturais e críticos, produzidos por Benedito Nunes.

9 Entrevista concedida ao jornalista José Castello, publicada no jornal O Estado de São Paulo e apresentada na mesma obra citada anteriormente.
} 
importância do Relato de um certo Oriente, de Milton Hatoum?", o crítico afirma ser a desterritorialização, que considera uma das qualidades do escritor, aludindo novamente ao procedimento narrativo que garante aproximar o leitor ao cenário amazônico, mantendo-o, entretanto, à distância:

[...] A distância está mais na elaboração. O romance se transforma na busca de um tempo perdido, mas em local bem delineado, pintados com tintas que não são regionalistas. Em dado momento, Milton descreve o quintal de uma casa e, ali, o leitor defronta com todo o mundo amazônico. Esse mundo aparece também nas recordações de seus personagens. Mas há, sempre, um distanciamento reflexivo que confere grandeza ao texto. (NUNES, 1996 apud NUNES, 2012, p. 232).

Como se viu, a obra de Hatoum não é considerada regionalista, nem por Benedito Nunes nem por Alfredo Bosi. Já Tânia Pellegrini (2007) argumenta que se trata de um regionalismo revisto, no sentido de que o autor revisita em suas ficções a Amazônia dos tempos da infância.

Também Schøllhammer (2009), em seu livro sobre a ficção brasileira contemporânea, anota que Hatoum logrou reunir em sua escritura o pensamento de extrato culturalista, que passou a dominar parte do cenário intelectual e literário no Brasil das últimas décadas do século passado, e uma dada renovação da vertente regionalista da ficção nacional. Em boa parte, portanto, a razão do êxito talvez resida, por um lado, em certa exaustão do experimentalismo formal no cenário literário, e, por outro lado, na difusão, entre o meio acadêmico e crítico, desde a década de 80 , dos estudos culturais, que garantiram a adoção de perspectiva multicultural no trato e problematização das questões relativas à identidade nacional.

\footnotetext{
Uma explicação para a popularidade da literatura de Hatoum encontra-se na convergência entre um certo regionalismo sem exageros folclóricos e o interesse culturalista na diversidade brasileira que, nas últimas décas, substituiu a temática nacional. (SCHØLLHAMMER, 2009, p. 87)
}

Assim, segundo o crítico, se este aspecto contribui para entender o sucesso editorial de sua obra, cumpre lembrar que os traços do regionalismo amazonense encontrados em sua obra podem também ser lidos, conforme SCHØLLHAMMER ( 2009) nos livros de Márcio Souza, bem como o fulcro memorialista que recupera a 
história das migrações no país é igualmente localizável em obras como a de Raduan Nassar, Lavoura arcaica..

Acrescenta ainda que Hatoum herda algo da tradição ficcional latino-americana, especialmente daquela centrada nos "romances tipo 'novela de la tierra' gênero que corresponde ao regionalismo brasileiro, em direção à descoberta do real maravilhoso e do realismo mágico (..). " (SCHØLLHAMMER, 2009, p. 89). Não descura, todavia, de estilo próprio que recorre ao emprego de estruturas narrativas complexas, resultante da enunciação a partir de vozes e focalização múltiplas, abolindo, o exotismo e, simultaneamente, valorizando referências históricas diversas. Destaca, ainda, que o projeto literário do escritor amazonense reside na “[...] sua vontade narradora [...] carregando uma certa nostalgia reativa, uma certa falta de humor, que talvez o impeça de ser aquele grande fabulador que Jorge Amado foi [...]" (SCHØLLHAMMER, 2009, p. 92).

Por sua vez, o escritor e crítico literário Dolhnikoff (2009), em seu texto Milton Hatoum e a condição extemporânea do romance, mostra personalidade crítica ao afirmar veementemente que Órfãos do Eldorado não é uma novela, como é afirmado na orelha do livro, mas que, segundo ele, é um romance curto, o qual revela o domínio do gênero pelo autor. Trata, outrossim, do estilo da escrita, denotando que Hatoum o compõe com linguagem sutil e poetizada. No entanto, ressalva que nem tudo é perfeito nesta obra, uma vez que o autor excede nas repetições ao mito da cidade encantada.

Já para Maria Zilda Ferreira Cury (2002), professora, pesquisadora e crítica literária, a obra de Hatoum revela a negociação das representações identitárias, travadas entre imigrantes e nativos, como uma maneira de construções alternativas das falas, principalmente, segundo ela, de personagens femininas: "Sobretudo através de suas personagens femininas, Milton Hatoum compõe em seus textos um canto, tocata e fuga de mil relatos e de outros tantos orientes" (CURY, 2002, p. 317).

Diante do exposto acima, com diferentes posições (ou não) sobre as obras, notamos que a crítica literária tem revelado grande apreço pela produção hatouniana. Entre os estudos universitários, ela tem servido de objeto para inúmeras pesquisas, como ensaios, resenhas, artigos, trabalhos de conclusão de curso, dissertações de mestrado e teses de doutorado. 
Sendo assim, destacar-se-á alguns estudos produzidos sobre as obras de Milton Hatoum, entre $\operatorname{artigos}^{10}$, dissertações e tese, buscando perceber o olhar crítico dos estudiosos, principalmente em relação ao que se tem discutido anteriormente, quanto ao caráter regionalista ou não regionalista do autor, à associação entre experiências e ficção e à ruptura de estereótipos presentes ou não nas obras do autor.

Dentre os estudiosos que consideram Hatoum um escritor regionalista, destacam-se Silva e LaGuardia (2011), as quais argumentam que Hatoum, além de mostrar temas vinculados à cultura, memória e identidade, aborda temáticas voltadas ao regionalismo.

Em oposição a essa ideia, os estudiosos Leão (2005) e Birman (2007) destacam que a ficção de Hatoum ultrapassa o registro regional. O primeiro, em sua dissertação ${ }^{11}$ de mestrado, argumenta que Hatoum fala, em sua ficção, da manifestação da diferença e da alteridade e do espaço amazônico como elementos de interação com o enredo, não como um adorno para enaltecer a cultura local, rejeintando, assim, a possibilidade de o autor ser considerado regionalista. E a segunda, em sua tese de doutorado, destaca que o autor não cristaliza a imagem dos povos (árabes e amazônicos) por meio de estereótipos e não aborda o espaço amazônico sob a ótica do exótico. E ainda acrescenta:

[...] Hatoum não subordina seu projeto literário a paisagens, formas e temas característicos da literatura de sua região, não se preocupando em reafirmar por meio de sua obra seu vínculo com a Amazônia, Manaus ou a nacionalidade brasileira. Se os traços brasileiros ou amazônicos surgem em seu texto, como certamente o fazem, estes não o determinam e sujeitam. Ou seja, sua literatura não busca documentar nem descrever o pedaço de Brasil que ela recorta e recria. E seus significados não estão depositados numa

\footnotetext{
${ }^{10}$ Segue uma lista de artigos, referentes à obra de Milton Hatoum, que não foram abordados aqui neste trabalho, mas que podem servir de pesquisa a outros estudos: "O grito dos excluídos em Milton Hatoum" (SANTOS, 2015); "A casa libanesa e o universo manauara: uma leitura topoanalítica da obra Dois irmãos, de Milton Hatoum" (ASSIS; KHALIL. s/d); "Regionalismo ou regionalidade?: Uma leitura do romance Cinzas do norte, de Milton Hatoum" (MIRANDA, 2013).

${ }^{11} \mathrm{O}$ fato de abordarmos, aqui, apenas uma dissertação não quer dizer que não existam outras dissertações sobre o conjunto de obras do autor Milton Hatoum. Pelo contrário, há outros estudos dissertativos com esse enfoque. Porém, aqui, o nosso objetivo não é exaurir todos os posicionamentos e estudos a esse respeito, mas fazer um apanhado sobre o que pensam determinados estudiosos e críticos sobre as obras hatounianas, para que possamos ter uma visão geral da recepção crítica dessas obras. A seguir traremos uma relação de outras dissertações, facilmente encontradas na internet, caso seja de interesse pesquisá-las: "Espaço e identidade: a relação entre espaço e personagens em Cinzas do Norte e Órfãos do Eldorado em Milton Hatoum" (BOECHAT, 2011); "Exílio e memória na narrativa de Milton Hatoum" (VIEIRA, 2007); "A ficção em ruínas em Milton Hatoum" (FRANCISCO, 2007); "Memória de uma Casa em um certo Oriente: leitura comparativa dos romances Crônicas da Casa Assassinada, de Lúcio Cardoso, Relato de um certo Oriente, de Milton Hatoum" (GEAMPAULO, 2015) e "Relações de gênero no romance de Milton Hatoum" (SILVA, 2011).
} 
exterioridade, que ela se limita a reduplicar, apagando-se como linguagem. Pelo contrário, sua linguagem é fortemente marcada pela auto reflexividade e pelo questionamento de suas próprias possibilidades. (BIRMAN, 2007, p. 52)

Assim, observa-se a autora defender um ficcionista que não se encaixa no regionalismo, já que o autor não descreve cenas tipicamente amazônicas, não busca destacar o exótico, o esperado, em relação à construção de discursos cristalizados e preconceituosos quanto a esse espaço. Pelo contrário, a pesquisadora enfatiza a linguagem do autor que se mostra crítica, reflexiva, que causa estranhamento, que se dirige ao limite, que recria e desnaturaliza espaços, identidades e culturas.

Quanto aos pesquisadores que associam a vida de Hatoum e sua ficção, elencase Lemos e Toneto (2012), Iegelski (2006) e Remundini e Wiginescki (2011). No primeiro estudo é argumentado que "[...] é sobre a Amazônia que recaem as escolhas de Hatoum, como se, em analogia aos próprios protagonistas que cria, o autor não escapasse às 'determinações' de sua história [...]” (LEMOS; TONEDO, 2012). No segundo, Hatoum é entendido como escritor tradutor de suas experiências e, assim, inventor de uma história que não possui a intenção da transposição exata do vivido, que é resultado da transcendência do mundo interno ao externo, num jogo entre mímese e expressão. E os últimos defendem que a construção de uma narrativa detalhada, minuciosa e ilustrativa em Cinzas do Norte é consequência da presença das lembranças do escritor.

Em relação à ruptura de estereótipos vislumbrada na ficção de Hatoum, especialmente em relação ao feminino, o artigo, de Santos e Macieira (2013), Alteridade e feminino no romance Dois irmãos de Milton Hatoum, chama a atenção à forma que Hatoum desconstrói o paradigma do pensamento, mostrando a mulher árabe como não submissa e não adepta ao islamismo, e, ainda, ao mostrar a mulher indígena fora do espaço da floresta. Sob outro aspecto, Albuquerque (2006) acredita que, nas narrativas de Hatoum, o poder do pater famílias está obscurecido pela força das personagens femininas, principalmente em relação às duas primeiras obras, mas que, em Cinzas do Norte, tal poder ganha mais espaço, por meio da figura dos militares. O mesmo diz vislumbrar a permanência do patriarcado ao perceber a mulher tendo como espaço o lar e o homem cuidando das finanças e do comércio e que a relação feminino/masculino tem o sexo como elemento de troca estabelecido pelas mulheres. Tem-se que considerar que tais posicionamentos são sob aspectos diferenciados do feminino e se acredita que 
há, sim, uma ruptura em relação ao que diz respeito à religiosidade da mulher árabe. E quanto ao estereótipo da mulher indígena e em relação às mulheres árabes, representada nas obras de Hatoum, julga-se que o fato delas se situarem no espaço do lar, não quer dizer que estejam numa relação de submissão, pois as mesmas se mostram donas de si, impondo suas vontades aos esposos, características, também reconhecidas por Albuquerque (2006). Assim, ambos os trabalhos dialogam em visualizar a mulher oriental detentora de um discurso visível, assumindo um poder perante ao outro. Porém, Albuquerque (2006) argumenta que as matriarcas, obtêm uma certa autonomia por meio da sedução. Assim, entende-se que, para este estudioso, o poder é dividido entre a mulher sedutora e o esposo que administra as finanças. No entanto, julga-se ser mais coerente o estudo empreendido por Santos e Macieira (2013), por se concordar com a defesa da quebra de paradigmas em relação ao feminino, os quais já foram referidos acima. Ainda mais por se notar a quebra de outro paradigma: a mulher assumindo a direção de um empreendimento, como exemplo, a personagem Rânia, em Dois Irmãos, a qual assume o papel de comerciante astuta. Desse modo, contrapõe-se aos padrões que regulam a representação social da mulher na época: a dona de casa.

Vê-se, nas discussões acima, a maneira como a obra de Hatoum foi acolhida pelo público leitor, pelos críticos e cientistas acadêmicos. Vislumbra-se que apesar de alguns estudiosos considerarem o escritor Hatoum como regionalistas, a maioria considera o contrário e, também, percebe-se que há preponderância nas análises em associar as experiências de vida do autor à sua ficção. É importante lembrar que nenhum posicionamento, aqui tratado, revela um desapontamento quanto à qualidade das produções de Hatoum.

\section{Considerações finais}

Diante da pesquisa que se efetuou aqui quanto à recepção crítica, vale ressaltar que se concorda com os posicionamentos discutidos anteriormente, no que tange à qualidade da linguagem empreendida pelo autor e sua capacidade de envolver o leitor em discussões tão atuais por meio de uma escrita que conduz o leitor à reflexão sobre as relações familiares e seus conflitos, sobre o contato entre culturas e a miscigenação, trazendo como consequência, a tolerância ou intolerância ao outro. Outrossim, constata- 
se a abordagem do feminino, retratado nas obras, bem como do papel da mulher estrangeira e da condição da mulher indígena.

Majoritariamente, não se considera Hatoum escritor regionalista, pois diante de suas obras se é convidado a repensar o espaço amazônico como palco de contextos universais e históricos que não são exclusivos da região, como a ditadura ou ainda como as relações e os conflitos familiares. Outros aspectos tais como a colonização e a imigração, embora sejam pertinentes à Amazônia, podem igualmente ser vislumbrados em praticamente todo o país, como decorrência do modo pelo qual se processou a nossa história após a abolição da escravidão. Contudo, isto não implica dizer que o autor não aborda questões centrais à região; apenas, afirma-se que sua obra não se reduz à esta abordagem. Assim, há espaço para o autor tratar de assuntos próprios a Manaus em ruínas face à política de implantação do desenvolvimento industrial, além dos problemas de urbanização desenfreada e pobreza. O autor também conduz o leitor, nas entrelinhas e por meio da figura dos personagens indígenas, a imaginar a violência sofrida pelos índios no período de colonização e das missões jesuíticas, mostrando a proibição da língua materna em detrimento da língua geral, o desrespeito à cultura e crenças indígenas, estas percebidas quando as órfãs se acham obrigadas a adotarem a crença cristã.

Diante dos elementos discutidos até aqui, percebe-se, em sua obra, escritor com exímia sensibilidade, que debate assuntos diferenciados, mas interligados, que revela domínio absoluto do complexo jogo de vozes narrativas, logrando desenvolver pelo discurso ficcional aspectos da memória de personagens e da própria história do país. Finalmente, por meio da pesquisa aqui realizada, nota-se o quanto a obra de Hatoum desperta interesse em estudos e pesquisas.

\section{REFERÊNCIAS:}

ALBUQUERQUE, G. Um autor, várias vozes: identidade, alteridade e poder na narrativa de Mílton Hatoum. Estudos de Literatura Brasileira Contemporânea, Brasília, $\mathrm{n}^{\circ}$. 28. p. 125-140, julho-dezembro, 2006.

BIRMAN, D. Entre-narrar: relatos da fronteira em Milton Hatoum. Rio de Janeiro, 2007. Tese (Doutorado em Literatura Comparada) - Faculdade de Letras, Universidade Federal do Rio de Janeiro, 2007. $290 \mathrm{f}$.

BOSI, A. História concisa da literatura brasileira. 49ª ed. São Paulo: Cultrix, 2013. BRASIL DE FATO. Quando o mito vira história e a história vira mito. São Paulo, 2010. Disponível em: < http://www.miltonhatoum.com.br/sobre-autor/noticias- 
entrevistas/quando-o-mito-vira-historia-e-a-historia-vira-mito-entrevista-ao-brasil-defato>. Acesso em 31 de outubro de 2015.

CURY, M. Z. F. Imigrantes e agregadas: personagens femininas na ficção de Milton Hatoum. In: DUARTE, C. L.; DUARTE, E. de A.; BEZERRA, K. da C. (Org.). Gênero e representação na literatura brasileira: ensaios. Belo Horizonte: Pós-Graduação em Letras Estudos Literários, UFMG, 2002.

DOLHNIKOFF, L. Milton Hatoum e a condição extemporânea do romance. Revista Sibila: Revista de poesia e crítica literária. Ano 15, 2009. Disponível em: http://sibila.com.br/critica/milton-hatoum-e-a-condicao-extemporanea-doromance/2180. Acesso em: 06 de jan. de 2016.

GRAIEB, C. Milton Hatoum cria pátria entre dois mundos. O Estado de S. Paulo. São Paulo, ano: IX, $\mathrm{n}^{\mathrm{o}}$ 2950, março, 1995. Disponível em: <http://www.miltonhatoum.com.br/wpcontent/uploads/2011/03/Caderno2_mar\%C3\%A 7095.jpg>. Acesso em: 31 de out. de 2015.

HATOUM, M. A noite da espera. Companhia das Letras, 2017. Cinzas do Norte. São Paulo: Companhia das Letras, 2010. . Dois irmãos. São Paulo: Companhia das Letras, 2006.

Entrevista/Milton Hatoum. Correio Braziliense. Brasília, julho, 2005. Disponível em: < http://www.miltonhatoum.com.br/wp content/uploads/2011/03/DoisIrm\%C3\%A3os_CorreioBraziliense_2005.jpg>. Acesso em: 31 de out. de 2015. Órfãos do Eldorado. São Paulo: Companhia das Letras, 2008. Relatos de um certo Oriente. São Paulo: Companhia das Letras, 2008.

IEGELSKI, F. Tempo e memória, literatura e história. Alguns apontamentos sobre Lavoura Arcaica, de Raduan Nassar e Relato de um certo Oriente, de Milton Hatoum. 2006. (Dissertação de mestrado em Língua, Literatura e Cultura Árabe) - Departamento de Letras Orientais da Faculdade de Filosofia, Letras e Ciências Humanas, Universidade de São Paulo, 2006.

LEÃO, A. Dois irmãos: um romance às margens do negro. 2005. (Dissertação de mestrado em Letras) - Universidade Federal de Santa Maria, 2005.

LEITE, S. H. T. de A. Memória e identidade nos romances de Milton Hatoum. Revista FIKR, v. 2, p. 16-34, 2010. Disponível em: <http://hdl.handle.net/11449/124928>. Acesso em 06 de jan. de 2016.

LEMOS e TONETO. Os labirintos da memória em "Órfãos do Eldorado" de Milton Hatoum. Revista Recorte. Mestrado em Letras: Linguagem, Discurso e Cultura / UNINCOR ANO 9 - N. ${ }^{\circ}$ 1, 2012.

NUNES, B. Do Marajó ao arquivo: breve panorama da cultura no Pará. Org. Victor Sales Pinheiro. Belém: Secult: Ed. Ufpa, 2012.

PELLEGRINI, T. Milton Hatoum e o regionalismo revisitado. In CRISTO, Maria da Luz Pinheiro de (Org.). Arquitetura da memória: ensaios sobre os romances Dois Irmãos, Relato de um Certo Oriente e Cinzas do Norte. Manaus: UNINORTE, 2007, p. 98-116.

REMUNDINI, E. C.; WIGINESCKI, K. A técnica memorialística no romance Cinzas do Norte, de Milton Hatoum. Anais do SILEL, Uberlândia: EDUFU, v. 2, nº 2, 2011.

REVISTA VISÃO. Recordações da casa dos mortos. Maio, 1989. Disponível em: < www.miltonhatoum.com.br/wp-content/uploads/2011/03/Relato_Visão.jpg>. Acesso em: 31 de outubro de 2015. 
SAMPAIO, A. Milton Hatoum: personagens em trânsito. Diário do Nordeste, Caderno 3, abril, 2009. Disponível em: <http://diariodonordeste.verdesmares.com.br/cadernos/caderno-3/milton-hatoumpersonagens-em-transito-1.743311>. Acesso em: 06 de jan. de 2016.

SANTOS, M. M.; MACIEIRA, M. do S. B. Alteridade e feminino no romance Dois irmãos de Milton Hatoum. Revista Fiar: Revista do Núcleo de Pesquisa e Extensão. Ariquemes, v.2 n. 1, p. 174-184, 2013.

SEREZA, H. C. Milton Hatoum canta Manaus para ser universal. O Estado de S. Paulo. Caderno 2, Seção: Literatura, maio, 2000. Disponível em: < http://www.miltonhatoum.com.br/sobre-autor/milton-hatoum-canta-manaus-para-seruniversal-por-haroldo-ceravolo-sereza-caderno-2-o-estado-de-sao-paulo-27-de-maio-de2000>. Acesso em: 31 de outubro de 2015.

SILVA, J.; LAGUARDIA, A. Mães zelosas, Cunhantãs resignadas, Amantes perigosas: representações da Mulher Amazônica no romance de Milton Hatoum. Somanlu, ano 11, n. 1, , p. 131-149, jan./jun. 2011.

TRIGO, L. Manaus, a personagem. $O$ Globo, maio, 2001. Disponível em: http://www.miltonhatoum.com.br/wp-content/uploads/2011/03/Manaus-apersonagem_GLOBO.jpg Acesso em: outubro de 2015.

Recebido em 24/05/2018

Aprovado em 07/07/2018 